\title{
Vitamin D deficiency among selected group of Sudanese housewives
}

\author{
Abstract \\ Justification: There is no published data about vitamin D deficiency among Sudanese \\ women with fertility problems.
}

Objectives: To know the prevalence of vitamin D deficiency between the participants

Material and method: Clinical-based descriptive cross sectional study, 73 Sudanese housewives with infertility disorder and vitamin D level was measured to each participant.

Result: $49.3 \%$ of the participants were vitamin D deficient.

Discussion: The study observed that high prevalence of vitamin D deficiency among the participants, although of their residence in sunny tropical country, vitamin D supplement may support the treatment of their infertility.

Conclusion: Further studies must be done with large sample size nationally and universal.

Keywords: vitamin D, deficiency, house wives, infertility, large, sample, country
Volume 8 Issue I - 2019

\author{
Mohammed A Gafoor A Gadir,' Mohammed \\ Omer Mohammed Hussein,' Mosab \\ Nouraldein Mohammed Hamad ${ }^{2}$ \\ 'Department of obstetrics and gynecology and reproduction, \\ Banoon center, Sudan \\ ${ }^{2}$ Department of health Sciences, Elsheikh Abdallah Elbadri \\ University, Sudan
}

\section{Correspondence: Mosab Nouraldein Mohammed Hamad, Department of Medical Parasitology, Faculty of Health Sciences Elsheikh Abdallah Elbadri University, Sudan,}

Emailmusab.noorl3@gmail.com

Received: January 25, 2019 | Published: February 21, 2019

\section{Introduction}

Vitamin D is produced from 7-dehydrocholesterol in the skin via UV-B radiation from the sun. This is an inactive form of vitamin D and needs two enzymatic hydroxylation reactions before activation. These are 25-hydroxylation and 1-a-hydroxylation. ${ }^{1}$ As the initial reaction takes place principally in the liver with 25 -hydroxylase, the second one occurs mainly in the kidneys with 1-a-hydroxylase (1, 25-dihydroxyvitamin $\mathrm{D}[1,25(\mathrm{OH}) 2 \mathrm{D} 3]) .^{2}$ This structure of vitamin $\mathrm{D}$ has a high affinity for binding to vitamin D receptors (VDRs) in target tissue (2). Kidney 1-a-hydroxylase enzyme works under the control of sex hormones and endocrine factors. ${ }^{3}$

Vitamin D is a key regulator of calcium phosphorus homeostasis and bone health. Lately, a number of non classical target organs including reproductive ones have been defined for vitamin D. VDRs are present in a range of tissue such as the immune system, endocrine system, and reproductive system. ${ }^{3}$ VDRs are there in both the cytoplasm and nucleus of granulosa cells in ovaries. ${ }^{4}$ The existence of VDRs in female reproductive tissue proposes that vitamin D may have a role in female reproductive functions.

AMH is a gonadal-specific glycoprotein created in females by granulosa cells throughout follicle growth. As it does not alter much over the menstrual cycle and is created by growing ovarian follicles, AMH is a helpful predictive marker in assisted reproductive technology (ART). Although AMH is believed to be one of the best diagnostic markers for ovarian reserve, studies have revealed that environmental factors such as vitamin D deficiency may change AMH expression and serum levels. ${ }^{5-7}$ In a study planning to find whether 1, 25(OH) $2 \mathrm{D} 3$ regulates AMH mRNA expression, a doserelated reduce was observed in AMH mRNA levels in granulosa cells following vitamin $\mathrm{D}$ treatment. Conversely, an increase was found in follicle-stimulating hormone (FSH) mRNA expression levels and cell proliferation. ${ }^{6}$ In a further study assessing the effects of 1, 25(OH) 2D3 in ovarian follicular development, changes were detected in AMH signaling in granulosa cells treated with $1,25(\mathrm{OH}) 2 \mathrm{D} 3$. A reverse association was observed between 25-hydroxyvitamin D (25(OH) D) levels in follicular fluid and AMH receptor-II (AMHR-II) mRNA gene expression. In females with inadequate $25(\mathrm{OH}) \mathrm{D}$ levels $(25(\mathrm{OH}) \mathrm{D}$ $<30 \mathrm{ng} / \mathrm{mL}$ ), a twofold raise in AMHR-II mRNA expression was detected. $^{5}$ The authors established that it also reduced the effect of AMH by decreasing phosphor S mad 1/5/8 nuclear localization. Cure with vitamin D may contrast the effect of AMH on granulosa cells and encourage the maturation of the follicles by inhibiting the AMHRII expression. ${ }^{5} \mathrm{AMH}$ levels may be lesser by $18 \%$ throughout winter as compared to summer. Throughout this season, vitamin D levels are also rather low down. ${ }^{6}$ It is supposed that low vitamin D levels may influence ovarian reserve and induce premature menopause in predisposed females. Additional, patients with premature ovarian insufficiency should take supplemental calcium and vitamin D for best bone health. The manufacture of sex hormones is controlled by multiple enzymes. Current studies have revealed that vitamin D may affect the expression and activities of some of this enzymes. ${ }^{8}$

PCOS is amongst the most widespread endocrine diseases that affect females in reproductive age. PCOS is a state that includes oligo and/ or ovulatory dysfunction and is distinguished by hyperandrogenism and polycystic ovarian morphology. ${ }^{9}$ The condition comprises numerous co-morbidities such as obesity, insulin resistance (IR), hyperinsulinemia, dyslipidemia, and ovulatory infertility. ${ }^{10} \mathrm{~A}$ few studies have recommended that vitamin D deficiency is more frequent among females with PCOS as compared to healthy individuals. ${ }^{11-13}$ Simultaneously, a meta-analysis establishes that vitamin D levels were not dissimilar between women with and without PCOS. ${ }^{14} \mathrm{Li}$ et al., ${ }^{14}$ establish lower vitamin D levels amongst females with PCOS. ${ }^{15}$ As an additional study revealed higher vitamin $\mathrm{D}$ levels between females with PCOS than in healthy individuals. ${ }^{16}$ There are an inadequate amount of studies documenting the uses of vitamin D supplementation for improving PCOS symptoms. Treatment with vitamin D is claimed to recover certain clinical and laboratory findings associated to PCOS such as menstrual frequency, follicular development, androgen levels, and IR. ${ }^{17,18}$ 
Primary dysmenorrhea is featured by the overproduction of prostaglandins in the uterus. The presence of VDRs in the uterus and the inhibition of prostaglandin synthesis by vitamin D may play a task in the treatment of primary dysmenorrhea. ${ }^{19,20}$

\section{Justification}

There is no published data about vitamin D Deficiency among Sudanese women with fertility disorders women.

\section{Objectives}

To know the prevalence of vitamin D deficiency between the participants

\section{Material and method}

\section{Study design}

Clinical based-descriptive cross sectional study

\section{Study area}

Banoon Center of obstetrics and gynecology and assisted reproduction, Khartoum, Sudan

\section{Study period}

July to November, 2017

\section{Study population}

Sudanese housewives with infertility problems attended to Banoon center during the study period.

\section{Sample size}

73 Sudanese housewives with infertility disorder

\section{Data collection}

Well constructed questionnaire was formed and filled by each participant.

\section{Ethical consideration}

Each participant was informed about the goal of the study and each one was consent to be involved in it.

\section{Statistical analysis}

The percentage of vitamin $\mathrm{D}$ deficient was measure by the following equation:

Vitamin D deficient/ total of participants X 100

\section{Results}

$49.3 \%$ of the participants were vitamin D deficient.

\section{Discussion}

Our result showed that high prevalence of vitamin D deficiency among those women with fertility disorders, despite of their living in a sunny country and their direct exposure to the sun light, that means vitamin D supplement may provide them with sufficient vitamin D and that may solve partially or completely their fertility problems.

\section{Conclusion}

Extra studies must be done with large sample size nationally and worldwide.

\section{Acknowledgments}

None.

\section{Conflicts of interest}

The author declares there are no conflicts of interest.

\section{References}

1. Nandi A, Sinha N, Ong E, et al. Is there a role for vitamin D in human reproduction? Horm Mol Biol Clin Investig. 2016;25(1):15-28.

2. Boisen IM, Bollehuus Hansen L, Mortensen LJ, et al. Possible influence of vitamin D on male reproduction. J Steroid Biochem Mol Biol. 2017;173:215-222.

3. Blomberg Jensen M. Vitamin D and male reproduction. Nat Rev Endocrinol. 2014;10(3):175-186.

4. Thill M, Becker S, Fischer D, et al. Expression of prostaglandin metabolising enzymes COX-2 and 15-PGDH and VDR in human granulosa cells. Anticancer Res. 2009;29(9):3611-3618.

5. Merhi Z, Doswell A, Krebs K, et al. Vitamin D alters genes involved in follicular development and steroidogenesis in human cumulus granulosa cells. J Clin Endocrinol Metab. 2014;99(6):E1137-E1145.

6. Dennis NA, Houghton LA, Jones GT, et al. The level of serum antiM€ullerian hormone correlates with vitamin D status in men and women but not in boys. J Clin Endocrinol Metab. 2012;97(7):2450-2455.

7. Malloy PJ, Peng L, Wang J, et al. Interaction of the vitamin D receptor with a vitamin D response element in the Mullerian-inhibiting substance (MIS) promoter: regulation of MIS expression by calcitriol in prostate cancer cells. Endocrinology. 2009;150(4):1580-1587.

8. Lundqvist, J. Vitamin D as a regulator of steroidogenic enzymes. F1000Research. 2014;3:155.

9. Goodman NF, Cobin RH, Futterweit W, et al. American Association of Clinical Endocrinologists, American College of Endocrinology, and Androgen Excess and PCOS Society Disease State Clinical Review: guide to the best practices in the evaluation and treatment of polycystic ovary syndrome-part 1. Endocr Pract. 2015;21(11):1291-1300.

10. March WA, Moore VM, Willson KJ, et al. The prevalence of polycystic ovary syndrome in a community sample assessed under contrasting diagnostic criteria. Hum Reprod. 2010;25(2):544-551.

11. Wehr E, Trummer O, Giuliani A, et al. Vitamin D-associated polymorphisms are related to insulin resistance and vitamin D deficiency in polycystic ovary syndrome. Eur J Endocrinol. 2011;164(5):741-749.

12. Mazloomi S, Sharifi F, Hajihosseini R, et al. Association between hypoadiponectinemia and low serum concentrations of calcium and vitamin D in women with polycystic ovary syndrome. ISRN Endocrinol. 2012;2012:949427.

13. Lerchbaum E, Giuliani A, Gruber HJ, et al. Adult-type hypolactasia and calcium intake in polycystic ovary syndrome. Clin Endocrinol (Oxf). 2012;77(6):834-843.

14. He C, Lin Z, Robb SW, Ezeamama A. Serum vitamin D levels and polycystic ovary syndrome: a systematic review and meta-analysis. Nutrients. 2015;7(6):4555-4577. 
15. Li HW, Brereton RE, Anderson RA, Wallace AM, Ho CK. Vitamin D deficiency is common and associated with metabolic risk factors in patients with polycystic ovary syndrome. Metabolism. 2011;60(10):1475-1481.

16. Mahmoudi T. Genetic variation in the vitamin $\mathrm{D}$ receptor and polycystic ovary syndrome risk. Fertil Steril. 2009;92(4):1381-1383.

17. Irani M, Minkoff H, Seifer DB, et al. Vitamin D increases serum levels of the soluble receptor for advanced glycation end products in women with PCOS. J Clin Endocrinol Metab. 2014;99(5):E886-E890.
18. Kumari KR, Hadalagi NM. Role of sunshine vitamin " $D$ " sufficiency in male and female infertility. Int J Reprod Contracept Obstet Gynecol. 2015;4(2):305-311.

19. Lasco A, Catalano A, Benvenga S. Improvement of primary dysmenorrhea caused by a single oral dose of vitamin D: results of a randomized, double-blind, placebo-controlled study. Arch Intern Med. 2012;172(4):366-367.

20. Dawood MY. Primary dysmenorrhea: advances in pathogenesis and management. Obstet Gynecol. 2006;108(2):428-441. 